\title{
A Virtual Differences in Face Recognition Techniques
}

\author{
Lakshmi Patil, V.D. Mytri
}

\begin{abstract}
Separated and other biometric security headways, altered face insistence gives a consistently normal and less unpredictable strategy for human obvious proof; at any rate it additionally shows continuously specific inconveniences. There are dependably varieties existing in face photographs of a similar subject individual, which are accomplished by various lighting conditions, various positions and appearances of the subject individual, various headings and spots of cameras and other erratic elements. Thus, face recognition is a challenging problem. In this paper, face recognition is implemented with a various methods such as PCA, LBP, SVD-HMM, LIN-SVDHMM approach on standard ORL database and the results are compared to find the most efficient method.
\end{abstract}

Keywords: Face recognition, PCA, LBP, SVD, HMM.

\section{INTRODUCTION}

Face certification is an incredibly testing appraisal region in PC vision and model solicitation in perspective on mixes in outward appearances, acts and illuminating. A couple of rising applications, from law execution to business endeavors, request the business to make gainful and robotized face authentication structures. Regardless, different experts have dealt with the issue of face insistence for a long time still a couple of moves should be settled. Parcel in enlightenment of the scene, changes in position, bearing and clarification are instances of a touch of the issues to be overseen warily. In like way when size of face database develops the affirmation time changes into an essential. Face certification is one of the biometric system that to have the upsides of both high accuracy and low discourteousness. It has the exactness of a physiological technique without being meddling. Along these lines, the face validation has drawn the plausibility of specialists in fields from security, Psychology, and picture overseeing, to $\mathrm{PC}$ vision. Different figurings have been proposed for face verification, Face attestation has moreover exhibited valuable in other sight and sound data overseeing locales. Facial confirmation breaks down the attributes of an individual's face pictures commitment through a pushed camcorder or online face getting. Over the long haul days we have to keep up when all is said in done security Information, in each affiliation or individual needs to improve their present security structure. A colossal piece of the individuals need better security structure which gives unbending security approach.

Now and again we find several plans concerning the repulsive practices of charge card duplicity, PC break-in by makers, or security parts in relationship, in shops, in government structures. In most by a wide edge of these awful rehearses the punks were mauling that hacking the data from business or quick access control structure. The frameworks don't allow access by which we are, at any rate by what we have, for example, ID cards, keys, passwords, PIN numbers. These systems they are really delineating us or they essentially need to affirm us. It spurns Permission of owner's, copies, or gets these character accumulates, the individual being hinted will no uncertainty get to our information or our own remarkable property at whatever point they need.

Beginning late, improvement wound up open to permit check of veritable individual character. This improvement is arranged in a field called "biometrics". Biometrics is a structure for seeing individuals by utilizing a stand-isolated physiological trademark, for example, a magnificent carving, eye, face, and so on or social properties, e.g., voice and etch, and so on. Biometrics is the usage of PCs to see individuals, looking at the vast majority of the over individual practically identical characteristics and inside individual blends. Among the conspicuous biometric ID frameworks, physiological systems, for example, shocking carving, face, DNA are more energetic than methods in direct game plan like keystroke, voice print, and so on.

In this paper we are understanding the unmistakable face confirmation frameworks such as LBP, PCA, Well, HMW,SVD proposed by different scientists and contrasting the outcomes as far as precision.

This paper is sorted out into V segments, the area I gives Introduction to Face Recognition, section II describes the database used for face recognition. Section III describes implementation of face recognition using LBP, PCA, SVDHMM and LIN-SVD HMM with results, Section IV compares these methods and finally paper ends with conclusion in section $\mathrm{V}$.

\section{DATABASE}

The proposed work uses ORL (Olivetti Research Laboratory) database. Each person in the ORL database has 10 images of different facial expressions. Hence 5 mages of each person is used for training the HMM and remaining 5 images are used for testing.

Train images for each person: $[1,3,5,7,9]$

Test images for each person: $[2,4,6,8,10]$

There are 200 images in train and 200 images in test sets. 


\section{IMPLEMENTATION OF VARIOUS FACE RECOGNITION TECHNIQUES}

\section{Neighborhood Binary Pattern}

Neighborhood twofold structures (LBP) are a kind of visual descriptor used for sales in PC vision. The LBP feature vector, in its most simple structure, is made in the going with way:

Bit the isolated window into cells (for instance 16x16 pixels for each cell).

For each pixel in a cell, counterbalance the pixel with most of its 8 neighbors (to the opposite side top, Left-

focus, left-base, right-top, etc.). Search for after the pixels along a circle, i.e.clockwise or counter-clockwise. Where within pixel's value is more fundamental than the neighbor's value, express "0". Something different, make

"1". This gives a 8-digit twofold number (which is typically changed over to decimal for solace).

-Compute the histogram, by methods for telephone, of the repeat of each "number" occurring (i.e., each mix of which pixels are humbler and which are more essential than within). This histogram can be seen as a 256-dimensional part vector.

- Optionally systematize the histogram.

- Concatenate (systematized) histograms everything considered. This gives a section vector for the entire window.

- The section vectors are managed using the Support vector machine.

Table 1 shows the Matlab simulations of face recognition using LBP on ORL database and achieved $75.5 \%$ recognition rate as calculated belowRecognition rate of LBP on $\mathrm{ORL}=$ Number of Faces Correctly Recognized/Total number of Faces $=151 / 200=75.5 \%$.

Table 1: Results of face recognition using LBP

\begin{tabular}{|l|l|l|l|l|l|l|l|}
\hline $\begin{array}{l}\text { Tes } \\
\mathrm{t}\end{array}$ & $\begin{array}{l}\text { Reco } \\
\text { gniz } \\
\text { ed }\end{array}$ & $\begin{array}{l}\text { Tes } \\
\mathrm{t}\end{array}$ & $\begin{array}{l}\text { Reco } \\
\text { gnize } \\
\text { d }\end{array}$ & $\begin{array}{l}\text { Te } \\
\text { st }\end{array}$ & $\begin{array}{l}\text { Reco } \\
\text { gniz } \\
\text { ed }\end{array}$ & $\begin{array}{l}\text { Tes } \\
\text { t }\end{array}$ & $\begin{array}{l}\text { Reco } \\
\text { gniz } \\
\text { ed }\end{array}$ \\
\hline 1 & 18 & 11 & 11 & 21 & 21 & 31 & 31 \\
\hline 1 & 1 & 11 & 8 & 21 & 21 & 31 & 25 \\
\hline 1 & 1 & 11 & 11 & 21 & 40 & 31 & 31 \\
\hline 1 & 1 & 11 & 11 & 21 & 21 & 31 & 25 \\
\hline 1 & 1 & 11 & 11 & 21 & 21 & 31 & 25 \\
\hline 2 & 2 & 12 & 12 & 22 & 22 & 32 & 32 \\
\hline 2 & 2 & 12 & 12 & 22 & 22 & 32 & 32 \\
\hline 2 & 16 & 12 & 12 & 22 & 19 & 32 & 19 \\
\hline 2 & 2 & 12 & 12 & 22 & 22 & 32 & 32 \\
\hline 2 & 2 & 12 & 12 & 22 & 22 & 32 & 32 \\
\hline 3 & 3 & 13 & 13 & 23 & 40 & 33 & 33 \\
\hline 3 & 3 & 13 & 13 & 23 & 23 & 33 & 33 \\
\hline 3 & 3 & 13 & 13 & 23 & 21 & 33 & 33 \\
\hline 3 & 3 & 13 & 13 & 23 & 23 & 33 & 33 \\
\hline 3 & 3 & 13 & 13 & 23 & 23 & 33 & 13 \\
\hline 4 & 4 & 14 & 19 & 24 & 24 & 34 & 34 \\
\hline 4 & 4 & 14 & 14 & 24 & 16 & 34 & 34 \\
\hline 4 & 4 & 14 & 19 & 24 & 24 & 34 & 34 \\
\hline 4 & 4 & 14 & 14 & 24 & 24 & 34 & 34 \\
\hline 4 & 4 & 14 & 14 & 24 & 24 & 34 & 34 \\
\hline 5 & 40 & 15 & 15 & 25 & 25 & 35 & 35 \\
\hline 5 & 5 & 15 & 15 & 25 & 25 & 35 & 25 \\
\hline 5 & 5 & 15 & 15 & 25 & 25 & 35 & 25 \\
\hline & & & & & & & \\
\hline
\end{tabular}

\begin{tabular}{|l|l|l|l|l|l|l|l|}
\hline 5 & 5 & 15 & 15 & 25 & 25 & 35 & 25 \\
\hline 5 & 5 & 15 & 15 & 25 & 25 & 35 & 25 \\
\hline 6 & 6 & 16 & 16 & 26 & 26 & 36 & 19 \\
\hline 6 & 6 & 16 & 19 & 26 & 26 & 36 & 36 \\
\hline 6 & 23 & 16 & 25 & 26 & 26 & 36 & 36 \\
\hline 6 & 6 & 16 & 16 & 26 & 26 & 36 & 24 \\
\hline 6 & 23 & 16 & 16 & 26 & 40 & 36 & 36 \\
\hline 7 & 1 & 17 & 17 & 27 & 27 & 37 & 37 \\
\hline 7 & 7 & 17 & 17 & 27 & 27 & 37 & 37 \\
\hline 7 & 7 & 17 & 25 & 27 & 27 & 37 & 19 \\
\hline 7 & 7 & 17 & 17 & 27 & 27 & 37 & 19 \\
\hline 7 & 7 & 17 & 23 & 27 & 27 & 37 & 16 \\
\hline 8 & 8 & 18 & 18 & 28 & 28 & 38 & 38 \\
\hline 8 & 8 & 18 & 18 & 28 & 28 & 38 & 38 \\
\hline 8 & 8 & 18 & 18 & 28 & 19 & 38 & 38 \\
\hline 8 & 8 & 18 & 18 & 28 & 28 & 38 & 38 \\
\hline 8 & 8 & 18 & 18 & 28 & 19 & 38 & 38 \\
\hline 9 & 21 & 19 & 19 & 29 & 29 & 39 & 25 \\
\hline 9 & 9 & 19 & 19 & 29 & 29 & 39 & 39 \\
\hline 9 & 9 & 19 & 19 & 29 & 29 & 39 & 39 \\
\hline 9 & 9 & 19 & 19 & 29 & 29 & 39 & 25 \\
\hline 9 & 9 & 19 & 19 & 29 & 23 & 39 & 03 \\
\hline 10 & 10 & 20 & 19 & 30 & 30 & 40 & 38 \\
\hline 10 & 10 & 20 & 20 & 30 & 30 & 40 & 40 \\
\hline 10 & 10 & 20 & 20 & 30 & 30 & 40 & 05 \\
\hline 10 & 10 & 20 & 18 & 30 & 30 & 40 & 23 \\
\hline 10 & 10 & 20 & 20 & 30 & 30 & 40 & 05 \\
\hline
\end{tabular}

\section{B.Principle component Analysis}

In proposed work, the PCA is major for extraction of features of different organs in the got face picture. Head Component Analysis (PCA) is a technique to separate and dimensionally decline the data, high lighting their similarities and detachments. The endeavor of facial accreditation is detaching data signals (picture data) into a few classes (individuals). The data sign are particularly uproarious, yet the data pictures are not absolutely sporadic and paying little respect to their abberations there are structures which occur in any data signal (eyes, nose, mouth and the relative division between these things) these trademark features are called Eigen faces.

The face space is delineated by the "Eigen faces", which are the eigenvectors of the course of action of appearances. They can be removed out of exceptional picture data by systems for Principle Component Analysis (PCA). A general system to manage the PCA is to from the start handle the trademark

polynomial condition for all Eigen regards and after that find their standing apart eigenvectors from pass on head parts (PCs). By techniques for PCA one can change each and every one of a sort image of the game-plan set into a seeing Eigen face. An enormous piece of PCA is that standapart picture can be imitated from the strategy set by joining the Eigen faces.

The noteworthy objective of PCA is to decrease the bit of the workspace. So head parts are picked in a view that they 
contain a major extent of information.

The main steps of PCA are dense as searches for after:

1. Store up xi of a $\mathrm{n}$ dimensional instructive party $\mathrm{x}, \mathrm{I}$ $=1,2,3 \ldots \ldots, \mathrm{m}$

2. Find mean $\mathrm{mx}$ and subtract it from each dat point, $\mathrm{xi}$ $\mathrm{mx}$

3. System Covariance Matrix $\mathrm{C}=(\mathrm{xi}-\mathrm{mx})(\mathrm{xi}-\mathrm{mx}) \mathrm{T}$

4. Pick Eigen regards and eigenvectors of Holistic techniques the system c

5. Sort Eigen regards and looking in diminishing interest.

6. Select first $\mathrm{d}<=\mathrm{n}$ Eigen vectors and makes instructive collecting in new depiction.

7. Anticipated test picture is stood separated from each envisioned

getting ready picture and result is the orchestrating Image closest to the test picture

Table 2: Results of face recognition using PCA

\begin{tabular}{|l|l|l|l|l|l|l|l|}
\hline $\begin{array}{l}\text { Tes } \\
\mathrm{t}\end{array}$ & $\begin{array}{l}\text { Reco } \\
\text { gniz } \\
\text { ed }\end{array}$ & $\begin{array}{l}\text { Tes } \\
\mathrm{t}\end{array}$ & $\begin{array}{l}\text { Reco } \\
\text { gnize } \\
\text { d }\end{array}$ & $\begin{array}{l}\text { Te } \\
\text { st }\end{array}$ & $\begin{array}{l}\text { Reco } \\
\text { gniz } \\
\text { ed }\end{array}$ & $\begin{array}{l}\text { Tes } \\
\text { t }\end{array}$ & $\begin{array}{l}\text { Reco } \\
\text { gniz } \\
\text { ed }\end{array}$ \\
\hline 1 & 18 & 11 & 11 & 21 & 21 & 31 & 31 \\
\hline 1 & 1 & 11 & 8 & 21 & 21 & 31 & 31 \\
\hline 1 & 1 & 11 & 11 & 21 & 21 & 31 & 31 \\
\hline 1 & 1 & 11 & 11 & 21 & 21 & 31 & 31 \\
\hline 1 & 1 & 11 & 11 & 21 & 21 & 31 & 31 \\
\hline 2 & 2 & 12 & 12 & 22 & 22 & 32 & 32 \\
\hline 2 & 2 & 12 & 12 & 22 & 22 & 32 & 32 \\
\hline 2 & 16 & 12 & 12 & 22 & 22 & 32 & 32 \\
\hline 2 & 2 & 12 & 12 & 22 & 22 & 32 & 32 \\
\hline 2 & 2 & 12 & 12 & 22 & 22 & 32 & 32 \\
\hline 3 & 3 & 13 & 13 & 23 & 23 & 33 & 33 \\
\hline 3 & 3 & 13 & 13 & 23 & 23 & 33 & 33 \\
\hline 3 & 3 & 13 & 13 & 23 & 09 & 33 & 33 \\
\hline 3 & 3 & 13 & 13 & 23 & 23 & 33 & 33 \\
\hline 3 & 3 & 13 & 13 & 23 & 09 & 33 & 33 \\
\hline 4 & 4 & 14 & 19 & 24 & 24 & 34 & 34 \\
\hline 4 & 4 & 14 & 14 & 24 & 24 & 34 & 34 \\
\hline 4 & 4 & 14 & 19 & 24 & 24 & 34 & 34 \\
\hline 4 & 4 & 14 & 14 & 24 & 24 & 34 & 34 \\
\hline 4 & 4 & 14 & 14 & 24 & 24 & 34 & 34 \\
\hline 5 & 40 & 15 & 15 & 25 & 03 & 35 & 35 \\
\hline 5 & 5 & 15 & 15 & 25 & 25 & 35 & 40 \\
\hline 5 & 5 & 15 & 15 & 25 & 25 & 35 & 25 \\
\hline 5 & 5 & 15 & 15 & 25 & 25 & 35 & 15 \\
\hline 5 & 5 & 15 & 15 & 25 & 25 & 35 & 25 \\
\hline 6 & 6 & 16 & 16 & 26 & 26 & 36 & 17 \\
\hline 6 & 6 & 16 & 19 & 26 & 26 & 36 & 36 \\
\hline 6 & 23 & 16 & 25 & 26 & 26 & 36 & 36 \\
\hline 6 & 6 & 16 & 16 & 26 & 26 & 36 & 36 \\
\hline 6 & 23 & 16 & 16 & 26 & 26 & 36 & 36 \\
\hline 7 & 1 & 17 & 17 & 27 & 27 & 37 & 37 \\
\hline 7 & 7 & 17 & 17 & 27 & 27 & 37 & 37 \\
\hline 7 & 7 & 17 & 25 & 27 & 27 & 37 & 37 \\
\hline 7 & 7 & 17 & 17 & 27 & 27 & 37 & 37 \\
\hline 7 & 7 & 17 & 23 & 27 & 27 & 37 & 37 \\
\hline 8 & 8 & 18 & 18 & 28 & 28 & 38 & 38 \\
\hline 8 & 8 & 18 & 18 & 28 & 28 & 38 & 38 \\
\hline 8 & 8 & 18 & 18 & 28 & 28 & 38 & 38 \\
\hline 8 & 8 & 18 & 18 & 28 & 28 & 38 & 38 \\
\hline 8 & 8 & 18 & 18 & 28 & 37 & 38 & 23 \\
\hline 9 & 21 & 19 & 19 & 29 & 29 & 39 & 39 \\
\hline & & & & & & & \\
\hline
\end{tabular}

\begin{tabular}{|l|l|l|l|l|l|l|l|}
\hline 9 & 9 & 19 & 19 & 29 & 29 & 39 & 39 \\
\hline 9 & 9 & 19 & 19 & 29 & 29 & 39 & 39 \\
\hline 9 & 9 & 19 & 19 & 29 & 29 & 39 & 39 \\
\hline 9 & 9 & 19 & 19 & 29 & 29 & 39 & 39 \\
\hline 10 & 10 & 20 & 19 & 30 & 30 & 40 & 40 \\
\hline 10 & 10 & 20 & 20 & 30 & 30 & 40 & 05 \\
\hline 10 & 10 & 20 & 20 & 30 & 30 & 40 & 40 \\
\hline 10 & 10 & 20 & 18 & 30 & 30 & 40 & 05 \\
\hline 10 & 10 & 20 & 20 & 30 & 30 & 40 & 40 \\
\hline
\end{tabular}

Table 2 Shows the Matlab simulations for face recognition and has obtained 90\% Recognition rate. Accuracy of PCA on ORL= Number of Faces Correctly Recognized/Total number of Faces $=180 / 200=90 \%$.

\section{EXPLICIT VALUE DECOMPOSITION AND HIDDEN MARKOV MODEL \& RESULTS}

Explicit worth spoil (SVD) can be looked three immaculate perspectives. On one hand, one can trust it to be a system for changing related parts into a lot of uncorrelated ones that better uncover the different relationship among the essential information things. At the same time, SVD is a technique for seeing and referencing the estimations along which server farms demonstrate the most grouping. The third system for review SVD is that once we have perceived where the most collection is, it is conceivable to locate the best estimation of the primary server farms utilizing less estimations. As such, SVD can be viewed as a procedure for information decrease. The essential thought behind SVD is taking a high dimensional, exceptionally factor set of information shows and decreasing it a lower dimensional space that uncovered the substructure of the principle information significantly more clearly and requesting it from most combination to the least. SVD depends upon a theory from straight factor based math which says that a rectangular framework 'A' can be confined into the eventual outcome of three cross segments a reasonable framework 'U', a corner to corner grid' S', and the transpose of an even organize ' $\mathrm{V}$ ' . The theory is typically exhibited as

$$
\mathrm{A}_{\operatorname{mxn}}=\mathrm{U}_{\operatorname{mxx}} \mathrm{S}_{\operatorname{mxn}} \mathrm{V}^{\mathrm{T}} \mathrm{nxn}
$$

\section{Where, $\mathrm{U}^{\mathrm{T}} \mathrm{U}=\mathrm{I} \& \mathrm{~V}^{\mathrm{T}} \mathrm{V}=\mathrm{I}$}

The bits of $U$ are orthonormal eigenvectors of AAT, pieces of $\mathrm{V}$ are orthonormal eigenvectors of ATA and $\mathrm{S}$ is a corner to corner cross segment containing the square crucial foundations of eigen respects from $\mathrm{U}$ or $\mathrm{V}$ in bouncing interest.

A picture with $64 \times 64$ goals has a $S$ cross area with same estimations, which means 64 undeniable explicit attributes. It has been displayed that the centrality and data of a sign is by and large passed on by a few tremendous explicit attributes and their related vectors. To pick a touch of these coefficients as highlight, countless mixes of the particular attributes and different pieces of structures $\mathrm{U}$ and $\mathrm{V}$ were

Blue Eyes Intelligence Engineering

\& Sciences Publication 
assessed. It was discovered that SVD contains three networks (U, S and V) use of two first coefficients of lattice $S$ and first coefficient of structure $U$ as three highlights U11S22S11 associate each square have the best solicitation rate

\section{Algorithm of the proposed model}

1. First, the image from the database is obtained and converted to gray scale.

2. Secondly, the image is resized to around 50 percent of its one of a kind size. So as to diminish the computational unusualness.

3.In solicitation to reimburse the gleam effect and decline the salt racket, a nonlinear least demand static channel is used. The channel has a smoothing work and diminishes the picture information.

3. After all the preprocessing on the image, the image is disconnected into squares having a front of around 75 percent. The amount of squares removed from each image is given by condition

$$
\mathrm{T}=\{\mathrm{H}-\mathrm{L} / \mathrm{L}-\mathrm{P}\}+1
$$

Where, $\mathrm{H}=$ height of the image

$\mathrm{P}=\mathrm{L}-1 ; \mathrm{L}=$ overlap size.

4. SVD for each block obtained in the previous step is calculated and the value for $U 11, S 22, S 11$ are found.

Table 3: Recognized images by SVD-HMM when $\alpha=\mathbf{1 . 0}$

\begin{tabular}{|c|c|c|c|c|c|}
\hline $\begin{array}{l}\text { Person } \\
\text { in Test }\end{array}$ & $\mathrm{FE} 1$ & $\mathrm{FE}_{2}$ & FE 3 & $\mathrm{FE} 4$ & FE 5 \\
\hline 1 & 26 & 1 & 1 & 1 & 1 \\
\hline 2 & 2 & 2 & 2 & 2 & 2 \\
\hline 3 & 3 & 3 & 3 & 3 & 3 \\
\hline 4 & 4 & 4 & 4 & 4 & 4 \\
\hline 5 & 1 & 5 & 5 & 5 & 5 \\
\hline 6 & 6 & 6 & 6 & 6 & 6 \\
\hline 7 & 7 & 7 & 36 & 7 & 7 \\
\hline 8 & 8 & 8 & 8 & 8 & 8 \\
\hline 9 & 9 & 9 & 9 & 9 & 9 \\
\hline 10 & 4 & 10 & 10 & 10 & 10 \\
\hline 11 & 11 & 11 & 11 & 11 & 11 \\
\hline 12 & 12 & 12 & 12 & 12 & 12 \\
\hline 13 & 13 & 25 & 25 & 13 & 13 \\
\hline 14 & 14 & 14 & 14 & 14 & 14 \\
\hline 15 & 15 & 15 & 15 & 15 & 15 \\
\hline 16 & 16 & 16 & 16 & 19 & 19 \\
\hline 17 & 17 & 17 & 17 & 17 & 17 \\
\hline 18 & 18 & 18 & 18 & 18 & 18 \\
\hline 19 & 19 & 19 & 19 & 19 & 19 \\
\hline 20 & 20 & 20 & 20 & 33 & 20 \\
\hline 21 & 21 & 39 & 21 & 21 & 21 \\
\hline 22 & 22 & 22 & 22 & 22 & 22 \\
\hline 23 & 23 & 23 & 23 & 23 & 23 \\
\hline 24 & 24 & 24 & 24 & 24 & 24 \\
\hline 25 & 25 & 25 & 25 & 25 & 25 \\
\hline 26 & 26 & 26 & 26 & 26 & 26 \\
\hline 27 & 27 & 27 & 27 & 27 & 27 \\
\hline 28 & 28 & 28 & 28 & 28 & 28 \\
\hline 29 & 29 & 29 & 29 & 29 & 29 \\
\hline 30 & 30 & 33 & 30 & 30 & 30 \\
\hline 31 & 31 & 31 & 31 & 31 & 31 \\
\hline 32 & 32 & 32 & 32 & 32 & 32 \\
\hline 33 & 33 & 33 & 33 & 33 & 33 \\
\hline 34 & 34 & 34 & 34 & 34 & 34 \\
\hline 35 & 35 & 15 & 35 & 35 & 35 \\
\hline 36 & 36 & 36 & 36 & 36 & 36 \\
\hline 37 & 37 & 37 & 37 & 37 & 37 \\
\hline 38 & 38 & 38 & 38 & 38 & 38 \\
\hline 39 & 39 & 39 & 39 & 39 & 39 \\
\hline 40 & 40 & 40 & 40 & 40 & 18 \\
\hline
\end{tabular}

5.Each $\mathrm{U}, \mathrm{S} \& \mathrm{~V}$ value is then given to the HMM model for training and an HMM model for a person is generated.

6. Similarly HMM model for each person is generated and saved in the database for further comparison.

7. While testing, all the steps are repeated and an HMM model for the query image is found. This model is then compared with the available database to find the probable match.

Table 3 Shows the Matlab simulations for face recognition and has obtained $93.5 \%$ Recognition rate. Accuracy of SVD-HMM on ORL= Number of Faces Correctly Recognized/Total number of Faces $=187 / 200=$ 93.5\%.

A. Linear Singular Value Decomposition \& Hidden Markov Model (LIN-SVD-HMM)

In LIN-SVD-HMM approach has been proposed to increase the accuracy of the system. Instead of using the top two singular values, the linear combination of the singular values can be used with a linear combination factor as shown in Eqs. 12 and 13. It can be observed from Eqs. 8 and 9 that three singular values can be used to derive two pseudo singular values $S_{1}$ and $S_{2}$. Now the each state is defined with $\mathrm{U}(1,1), \mathrm{S}_{1}$ and $\mathrm{S}_{2}$ instead of $\mathrm{U}(1,1), \Psi_{1}$ and $\Psi_{2}$. With this approach, thequestion that remains is the value for $\alpha$. The optimum value for alpha is determined varying the value from 1.0 to 0.6 with a decrement of 0.1 . When the $\alpha$ is set to 1.0 , it is equivalent to using the $\mathrm{U}(1,1), \Psi_{1}$ and $\Psi_{2}$ to define the states.

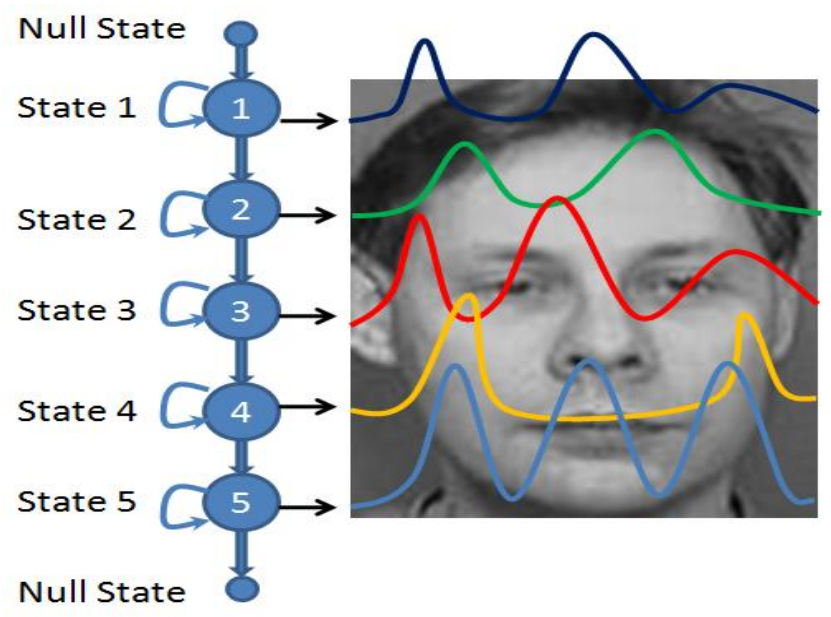

Fig 1: HMM distributions for each state

Each state in the face image can be approximated with a Gaussian mixture model as shown in Fig. 1,

$$
\Psi(x)=\sum_{j=1}^{J} p(j) \mathrm{N}_{k}(x)
$$

where, $\Psi(x)$ is a weighted sum of $\mathbf{J}$ Gaussian distributions and $\mathrm{N}_{k}(x)$ is the d-dimensional Gaussian distribution with mean $\mu$ and co-variance matrix $\Sigma$. 


$$
\begin{aligned}
& \beta_{1}+\beta_{2}+\beta_{3}+\ldots .+\beta_{n}=1 \\
& \mathrm{~N}_{k}(x \mid \mu, \Sigma)=\frac{1}{(2 \pi)^{\frac{d}{2}}|\Sigma|^{\frac{1}{2}}} e\left[-\frac{1}{2}(x-\mu)^{T} \Sigma^{-1}(x-\mu)\right]
\end{aligned}
$$

and

$$
\sum_{j=1}^{J} p(j)=1
$$

The state matrix $\Psi$ can be factorized into $U, S$ and $V$ matrices using the singular value decomposition. That is

$\Psi(x)=U S V^{T}$

Where $\mathrm{S}$ is the matrix of singular values $\Psi_{1}, \Psi_{2}, \Psi_{3}, \ldots . \Psi_{N}$ and it can be used as features in the HMM. Usually, thefeatures for the HMM can be selected from vectors of $U$ matrix and some of the singular values from $\mathrm{S}$ matrix. That is $\mathrm{U}(1,1), \Psi_{1}, \Psi_{2}, \Psi_{3}, \ldots, \Psi_{n}$. But in this work, instead of considering the singular values $\Psi_{1}$, $\Psi_{2}, \Psi_{3}, \ldots, \Psi_{n}$, the linear combination of the singular values are considered as the features. That is, the new features in a generalized form are,

$$
\begin{aligned}
& S_{i}=\beta_{i} \Psi_{i}+\beta_{i+1} \Psi_{i+1}+\beta_{i+2} \Psi_{i+2}+\ldots . .+\beta_{n} \Psi_{n} \\
& S_{i+1}=\beta_{i+1} \Psi_{i+1}+\beta_{i+2} \Psi_{i+2}+\beta_{i+3} \Psi_{i+3}+\ldots . .+\beta_{i+n} \Psi_{i+n}
\end{aligned}
$$

Where

$$
\sum_{n=1}^{N_{x}} \beta_{n}=1
$$

The values for $\beta_{n}$ can be derived with any optimization algorithm or by means of trial and error.

If the number of singular values to be considered only

to estimate $S_{i}$, then, the

$$
\begin{aligned}
& S_{1}=\alpha \Psi_{1}+(1-\alpha) \Psi_{2} \\
& S_{2}=\alpha \Psi_{2}+(1-\alpha) \Psi_{3}
\end{aligned}
$$

Where,

$$
\beta_{1}=\alpha \text { and } \beta_{2}=1-\alpha
$$

Table 4: Recognized images by LIN-SVD-HMM when $\alpha=1.0$

\begin{tabular}{|c|c|c|c|c|c|}
\hline $\begin{array}{c}\text { Person } \\
\text { in Test }\end{array}$ & FE1 & FE2 & FE3 & FE4 & FE5 \\
\hline 1 & 26 & 1 & 1 & 1 & 1 \\
\hline 2 & 2 & 2 & 2 & 2 & 2 \\
\hline 3 & 3 & 3 & 3 & 3 & 3 \\
\hline 4 & 4 & 4 & 4 & 4 & 4 \\
\hline 5 & 18 & 5 & 5 & 5 & 5 \\
\hline 6 & 6 & 6 & 6 & 6 & 6 \\
\hline 7 & 7 & 7 & 36 & 7 & 7 \\
\hline 8 & 8 & 8 & 8 & 8 & 8 \\
\hline 9 & 9 & 9 & 9 & 9 & 9 \\
\hline 10 & 19 & 10 & 10 & 10 & 10 \\
\hline 11 & 11 & 11 & 11 & 11 & 11 \\
\hline 12 & 12 & 12 & 12 & 12 & 12 \\
\hline 13 & 13 & 25 & 25 & 14 & 13 \\
\hline 14 & 14 & 14 & 14 & 14 & 14 \\
\hline 15 & 15 & 15 & 15 & 15 & 15 \\
\hline 16 & 16 & 16 & 16 & 16 & 16 \\
\hline
\end{tabular}

\begin{tabular}{|c|c|c|c|c|c|}
\hline 17 & 17 & 17 & 17 & 17 & 17 \\
\hline 18 & 18 & 18 & 18 & 18 & 18 \\
\hline 19 & 19 & 19 & 19 & 19 & 19 \\
\hline 20 & 20 & 20 & 33 & 33 & 20 \\
\hline 21 & 21 & 21 & 21 & 21 & 21 \\
\hline 22 & 22 & 22 & 22 & 22 & 22 \\
\hline 23 & 23 & 23 & 23 & 23 & 23 \\
\hline 24 & 24 & 24 & 24 & 24 & 24 \\
\hline 25 & 25 & 25 & 25 & 25 & 25 \\
\hline 26 & 26 & 26 & 26 & 26 & 26 \\
\hline 27 & 27 & 27 & 27 & 27 & 27 \\
\hline 28 & 28 & 28 & 28 & 28 & 28 \\
\hline 29 & 29 & 29 & 29 & 29 & 29 \\
\hline 30 & 30 & 33 & 30 & 30 & 30 \\
\hline 31 & 31 & 31 & 31 & 31 & 31 \\
\hline 32 & 32 & 32 & 32 & 32 & 32 \\
\hline 33 & 33 & 33 & 33 & 33 & 33 \\
\hline 34 & 34 & 34 & 34 & 34 & 34 \\
\hline 35 & 35 & 9 & 35 & 35 & 35 \\
\hline 36 & 36 & 36 & 36 & 36 & 36 \\
\hline 37 & 37 & 37 & 37 & 37 & 37 \\
\hline 38 & 38 & 38 & 38 & 38 & 38 \\
\hline 39 & 39 & 39 & 39 & 39 & 39 \\
\hline 40 & 40 & 40 & 40 & 40 & 40 \\
\hline 4 & & & & \\
\hline
\end{tabular}

Table 4 Shows the Matlab simulations for face recognition and has obtained 93.5\% Recognition rate.Accuracy of SVD-HMM on ORL $=$ Number of Faces Correctly Recognized/Total number of Faces $=189 / 200=$ $94.5 \%$.

\section{COMPARISONS}

\begin{tabular}{|l|l|l|}
\hline $\begin{array}{l}\text { SI. } \\
\text { No }\end{array}$ & Technique & $\begin{array}{l}\text { Recognition } \\
\text { Rate }\end{array}$ \\
\hline 1. & LBP & $75.5 \%$ \\
\hline 2. & PCA & $90 \%$ \\
\hline 3. & SVD-HMM & $93.5 \%$ \\
\hline 4. & LIN-SVD-HMM & $94.5 \%$ \\
\hline
\end{tabular}

\section{CONCLUSION}

In this paper, another framework is proposed subject to the secured markov models. The HMM models are made dependent on the single worth debilitating. The highlights are ousted utilizing the solitary qualities. In the proposed methodology, the best singular values are linearly combined to define the features. In original SVD-HMM, the singular values are directly used, but in the proposed LIN-SVDHMM, the singular values are linearly combined instead. In LIN-SVD-HMM, three singular values are used while only two singular values are used in SVD-HMM. The accuracy of the recognition is tested for two different datasets formed with ORL database. In both the cases, the accuracy of LINSVD-HMM has yielded better accuracy than SVD-HMM. In case of the first data set (Training: 1,3,5,7 and 9), the accuracy of LIN-SVD-HMM was $96 \%$ whereas, the accuracy of SVD-HMM was 94\%. Similarly, for second data set (Training: 1,3,6,8 and 9), the accuracy of LIN-SVD-

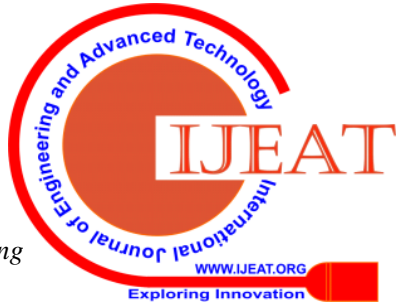


HMM was $94.5 \%$ whereas; the accuracy of SVD-HMM was 93.5\%. The SVD-HMM based methods are also compared with the PCA and LBP for these datasets. Hence, the proposed method using the linear combination of singular values (LIN-SVD-HMM) has much better accuracy than the SVD-HMM, PCA and LBP

\section{REFERENCES}

1. Ara V Nefian, Monson H Hayes," Face conspicuous confirmation and Recognition utilizing Hidden Markov Model'. General Journal of Scientific and Research Publications, Volume 6, Issue 7, July 2016441 ISSN 2250-3153.

2. Ara V Nefian, Monson H Hayes ,"Face Recognition utilizing Embedded HMM", fourth International Colloquium on Signal Processing and its Applications, March 7-9, 2008, Kuala Lumpur, Malaysia. ISBN: 978 983-42747-9-5.

3. .Ara V Nefian, Monson H Hayes," An Embedded HMMBased Approach for Face Detection and confirmation", International Journal of Modern models In Engineering and Research", ISSN:2349-9745.

4. Fawzia A. E. Mansur" Review on Face Recognition Using Fuzzy Logic Hidden Markov and Neural Network Techniques", Research article In Applied Sciences elucidation 1,04 Dec 2017.

5. Ariful Islam" Face Detection Using Artificial Neural Network", International Journal Of Research In Engineering And Applied Sciences, Volume 1, Issue 8 (2016, AUGUST) (ISSN-2455-6300).

6. Nidal F. Shilbayeh and Gaith A. AL- Qudah," Face Detection System Based on MLP Neural Network", Recent Advances in Neural Networks, Fuzzy Systems and Evolutionary Computing, ISSN: 1790-5109, ISBN: 978-960-474-195-3.

7. P. Jonathon Phillips," Support Vector Machines Applied to Face Recognition", International Journal of Engineering and Technology Vol.1(2), 2009, 77-85.

8. Mrs. Swati y Raut ,Mrs.Dipti.A.Doshi," A face assertion structure by secured markov model and discriminingset approach", International Journal of Scientific and Engineering Research, Volume 6, Issue 1, January-2015 30 ISSN 2229-5518.

9. Paliy, A. Sachenko, V. Koval, Y. Kurylyak," Approach to Face Recognition Using Neural Networks", IEEE Workshop on Intelligent Data Acquisition and Advanced Computing Systems: Technology and Applications,7 September 2005, Sofia, Bulgaria.Yi- Qiong Xu, Bi-chang li, Bo-Wang,"Face Detection and Recognition using Neural Networks and Hidden Markov Model", IEEE International conference on Signal Processing and neural Networks, 14-7-2003.

10. Sandeep Saxena, Dr. Mansaf Alam, Dr. B. Mohd. Jabarullah3, Dr. Rakesh Kumar Yadav," Face Recognition Using Coupled the Hidden Markov Model With An Artificial Neural Network", IOSR Journal of Computer Engineering (IOSR-JCE) e-ISSN 22780661,p-ISSN: 2278-8727, Volume 20, Issue 1, Ver. III (Jan.- Feb. 2018), PP 08-15.

11. Manisha M. Kasar, Debnath Bhattacharyya and Tai-hoon Kim," Face Recognition Using Neural Network: a Review", International Journal of Security and Its Applications Vol. 10, No. 3 (2016).

\section{AUTHORS PROFILE}

Lakshmi Patil Research scholar, Appa Establishment of Engineering and Technology, Klb, Karnataka, India.

V.D. Mytri Principal, Appa Establishment of Engineering and

Technology, Klb, Karnataka, India. 